\title{
OBLIGATORIEDAD DE LA JURISPRUDENCIA EN MÉXICO Y EL CONTROL DE CONVENCIONALIDAD
}

\author{
OBLIGATORY OF JURISPRUDENCE IN MEXICO AND THE CONTROL OF \\ CONVENTIONALITY
}

\author{
María de-los-Santos Torres-Chan ${ }^{1 *}$ \\ 1. Escuela Judicial del Estado de Tabasco, México.tcms_11@hotmail.com \\ * Autor de correspondencia: María de-los-Santos Torres-Chan, correo electrónico: tcms_11@hotmail.com
}

\section{RESUMEN}

No se puede concebir un sistema jurídico sin transformaciones; la globalización, el avance tecnológico y educativo han influido en la forma de impartir y administrar justicia, lo que hasta hace unas décadas se vislumbraba estático, es susceptible de diversas interpretaciones, generando la inclusión o reconocimiento de nuevos derechos en busca de la protección más amplia a la persona. Al hablar de la evolución del sistema jurídico en México, es obligatorio referirse al control de convencionalidad y la obligatoriedad de la jurisprudencia, dos herramientas que coadyuvan en la labor jurisdiccional, pero que generan disyuntivas en los juzgadores en los casos en que la jurisprudencia es contraria a los ordenamientos convencionales, pues surgen dilemas como la obligatoria de aplicación de la jurisprudencia que contraviene derechos consagrados en instrumentos internacionales o bien desaplicar ante el deber de los juzgadores de aplicar el control de convencionalidad.

Palabras clave: Convencionalidad; inconvencionalidad; derechos humanos; interpretación jurídica.

Cómo citar:

Torres-Chan, María de-los-Santos. (2021). Obligatoriedad de la jurisprudencia en méxico y el control de convencionalidad. Revista de Investigaciones Universidad del Quindí, 33(S2), 83-90. https://doi.org/10.33975/riuq.vol33nS2.616 


\section{ABSTRACT}

A legal system cannot be conceived without transformations; Globalization, technological and educational progress have influenced the way of imparting and administering justice, which until a few decades ago seemed static, is susceptible to various interpretations, generating the inclusion or recognition of new rights in search of the broadest protection to the person. When talking about the evolution of the legal system in Mexico, it is mandatory to refer to the conventionality control and the obligatory nature of the jurisprudence, two tools that contribute to the jurisdictional work, but that generate dilemmas in the judges in cases where the jurisprudence is contrary. to conventional legal systems, since dilemmas arise such as the mandatory application of jurisprudence that contravenes rights enshrined in international instruments or to disengage before the duty of the judges to apply the conventionality control.

Keywords: Conventionality; unconventionality; human rights; legal interpretation.

\section{INTRODUCCIÓN}

Los jueces mexicanos han experimentado diversas transformaciones en la forma de realizar su labor, hasta hace unos años, era impensable que sus interpretaciones se apartaran de las normas internas, hoy la realidad es distinta, los juzgadores se enfrentan a nuevos retos, derivados del deber de aplicar el principio pro persona.

Esta nueva forma de impartir justicia, obliga al conocimiento y aplicación no sólo de las normas de carácter interno sino de aquellos instrumentos internacionales que nuestro país ha suscrito y que reconocen derechos humanos, por tanto, cuando una ley nacional vulnera un derecho fundamental, es posible implicarla para dar paso aquella que establezca la más amplia protección.

Aun cuando esta facultad está reconocida por la Corte Interamericana de Derechos Humanos, el Pleno de la Suprema Corte de Justicia de la Nación ha negado a los juzgadores la posibilidad de inaplicar la jurisprudencia que restrinja o vulnere los derechos humanos, ello constituye un revés en el camino que se ha recorrido sobre el tema del control de convencionalidad (Bazán, 2011).

No es posible que un juez local pueda inaplicar una norma que ha pasado por un proceso legislativo y que en aras del irrestricto respeto a los derechos humanos no pueda desatender una jurisprudencia que los restringe.

La premisa anterior, justifica la importancia de este documento, en la que se expone la necesidad de garantizar y respetar labor interpretativa de los juzgadores que ha sido reconocida en el orden internacional, siempre en búsqueda de velar por la observancia de los derechos humanos, pues no se trata de una inaplicación arbitraria de la jurisprudencia, sino de un estudio razonado del porqué -en su caso- contraviene disposiciones que ofrecen una protección más amplia.

Entender que han quedado atrás los años en las que el derecho era inflexible, es avanzar hacia la realización del ideal de todo juzgador: la justicia. Además de otorgar a los justiciables la certeza que en sus procedimientos lejos de interpretaciones rígidas, existe una gama de regulaciones de las que se 
buscará aquella que ofrezca el mayor respeto a derechos fundamentales.

\section{METODOLOGÍA}

La obligatoriedad de la jurisprudencia en México y el control de convencionalidadhistórico, está basado en el método histórico que consiste en la búsqueda de antecedentes de la problemática, recopilando diversos materiales de información y examinado cada una de ellas para obtener información sobre la evolución histórica del derecho mexicano y la necesidad que el sistema jurídico mexicano tuvo para adoptar el modelo de control de convencionalismo y ser aplicado en México, el método documental valió para la búsqueda de información en fuentes doctrinales consistente en recopilar y analizar las diversas opiniones que los estudiosos del derecho tienen sobre el sistema de convencionalidad y la supremacía de esta ante la aplicación y obligatoriedad de las normas jurídicas en México, lo anterior, se consolido con la aplicación del método exegético a partir de la comparación e interpretación de confrontación jurídica.

\section{RESULTADOS}

\section{Obligatoriedad}

El estudio de las normas jurídicas no puede ni debe limitarse a los ordenamientos internos. La globalización y el reconocimiento de los derechos humanos ha dado paso a su estudio desde perspectivas constitucionales y convencionales. En México las leyes se originaron en las costumbres, los pueblos precolombinos crearon sus propias instituciones jurídicas, atendiendo a las necesidades de quienes ostentaban el poder y en menor escala a la de los moradores de aquella época.

En la época colonial la forma de aplicar el derecho respondió a los intereses de los conquistadores, destacando que las leyes fueron dadas por la corona a los pueblos indios en recopilaciones, sin que los encargados de aplicarlas pudieran ir más allá de lo establecido en ellas. Esta remembranza deja de manifiesto que los primeros aplicadores del derecho en el país, solo debían observar la legislación interna, criterio que perduró hasta hace algunas décadas, en las que se entendía que la Constitución era la Ley Suprema, sin que existiera un ordenamiento superior (Kelsen, 2009) y la facultad de interpretarla correspondía exclusivamente a la Suprema Corte de Justicia de la Nación.

Sin embargo, la participación cada vez más activa de México en el ámbito internacional llevó al máximo tribunal de justicia a debatir la ubicación jerárquica de los tratados internacionales, así en 1999, concluyó que estos se encuentran por encima de las leyes federales y en segundo plano respecto a la constitución federal (SCJN, 1999). Esta postura se mantuvo hasta que la Corte Interamericana de Derechos Humanos a través de diversas resoluciones hizo hincapié en la necesidad de aplicar los instrumentos internacionales de los que México forma parte, reconociendo a los jueces ordinarios la facultad de desaplicar las normas que contravengan derechos humanos.

Se trata de un nuevo paradigma, que trajo como resultado reformas a la Constitución Federal en 2011, la creación de la décima época del Semanario Judicial de la Federación (SCJN, 2011) y la obligación para los operadores jurídicos de observar el control de convencionalidad.

El control de convencionalidad, tiene dentro de sus orígenes el voto concurrente emitido por el destacado jurista mexicano Sergio García Ramírez en el caso Myrna Mack Chang Vs Guatemala, 
quien apunta que los Estados tienen responsabilidad global, que constituyen un todo integral y que no es posible entonces que la Corte obligue, sólo a alguno de sus órganos, sustrayendo a otros del "control de convencionalidad" que trae consigo la jurisdicción internacional (Corte IDH, 2003).

En el caso Tibi Vs. Ecuador (Corte IDH, 2004) se utilizó el mismo término para establecer que si los tribunales constitucionales controlan la "constitucionalidad", el tribunal internacional de derechos humanos resuelve acerca de la "convencionalidad" de esos actos.

En el caso de Vargas Areco vs. Paraguay (Corte IDH, 2006) el multicitado jurista sostuvo que la Corte Interamericana no pretendía convertirse en una nueva y última instancia para resolver una controversia presentada en el orden interno de un Estado, sino que "tiene a su cargo el "control de convencionalidad" fundado en la confrontación entre el hecho realizado y las normas de la Convención Americana.

La Corte Interamericana de Derechos Humanos, el caso Radilla Pacheco vs México (Corte IDH, 2009) consideró que, para la protección de los derechos de la Convención Americana, los tribunales nacionales, entonces, debían apegarse a la Convención Americana y al desarrollo de ésta, haciendo referencia al párrafo 124 del caso Almonacid, que habla sobre la obligación de los jueces de realizar el control de convencionalidad.

A esta sentencia internacional le siguieron las condenas al estado mexicano los casos Fernández Ortega, Cabrera García y Montiel Flores, Rosendo Cantú y otra, en las que la Corte Interamericana de Derechos Humanos refrendó el deber de los jueces locales de aplicar el control de convencionalidad. Ante ello la Suprema Corte de Justicia de la Nación emitió diversas jurisprudencias sobre el tema, en las que reconoció la facultad de los jueces ordinarios de aplicar el control de convencionalidad, buscando el mayor beneficio a la persona.

Como se lee, la jurisprudencia en México ha servido de apoyo en la interpretación de los grandes temas jurídicos, pero es de preguntarse ¿qué sucede cuando la jurisprudencia contraviene los tratados internacionales?

Al respecto el Pleno de la Suprema Corte de Justicia de la Nación al resolver la contradicción de tesis 299/2013, reiteró el carácter obligatorio de la jurisprudencia de los tribunales del Poder Judicial de la Federación, por así establecerlo la Ley de Amparo, por tanto, a pesar de que un juzgador de grado inferior puede declarar la inconvencional un precepto secundario del orden jurídico nacional, a consideración Corte no puede inobservar la jurisprudencia obligatorio, por las siguientes razones:

“(...) admitir que un órgano de menor jerarquía pueda revisar un criterio obligatorio que se dio como resultado de un ejercicio hermenéutico del contenido de una norma que, en el caso concreto, atendia un derecho humano previsto constitucional y convencionalmente relacionado con la presunción de inocencia que se decía conculcada por la disposición normativa que prevé el delito de contrabando presunto, determinando que no lo vulneraba, sería tanto como permitir distorsionar la certeza y la seguridad jurídica que genera la definición del tema vía jurisprudencia del ente dotado de facultades constitucionales para establecer la última palabra. Lo anterior, no implicaría que se desatienda el compromiso adquirido por nuestro país de ejercer un control de convencionalidad, bajo el principio pro homine, porque en el caso de que los Tribunales Colegiados, adviertan que una jurisprudencia de este Supremo Tribunal pudiera resultar inconvencional, existen medios y procedimientos contemplados en la propia legislación, para expresar sus cuestionamientos al 
respecto, como son el procedimiento de sustitución de jurisprudencia contemplado en el propio párrafo décimo del artículo 94 constitucional, o las solicitudes de ejercicio de la facultad de atracción -contenidas en el artículo 107, fracciones V último párrafo; $y$, VIII, inciso b), segundo párrafo, de la Constitución Federal, que permitirían que sea este mismo Tribunal el que determine si la jurisprudencia por él emitida no resulta apegada al marco de derechos fundamentales surgido a partir de la reforma de dos mil once al artículo $1^{\circ}$ constitucional”. (SCJN, 2014, p.8).

De lo transcrito se desprende que la mayoría de los ministros de la Suprema Corte ha justificado la necesidad de la jurisprudencia obligatoria, dejando como herramienta a los tribunales de rango inferior la denuncia de la inconvencionalidad de la tesis a efectos que sea modificada o sustituida.

Esta postura genera grave afectación al gobernado quien resentirá una sentencia a la luz de una tesis obligatoria susceptible de ser modificada por el órgano creador, auspiciada-según criterio del máximo tribunal- por el silencio de un juez que a pesar de advertir su inconvencionalidad tendrá que ceñirse a la misma afectando con plena conciencia los derechos fundamentales del interesado.

Esta problemática constituye la génesis de esta investigación, pues los juzgadores no pueden permanecer impasibles, negando su facultad de interpretación o adecuación de la norma al caso concreto, con apego a las convenciones o normatividad que garantiza la más amplia protección a la persona.

\section{Control de convencionalidad}

Las reformas de 2011 a la Constitución Política de los Estados Unidos Mexicanos, son consecuencia de la ratificación de México a diversos tratados internacionales en materia de Derechos Humanos, las cuales ocasionaron un desajuste en el sistema normativo interno, debido a que todos estos derechos contenidos en instrumentos internacionales tienen el carácter de supremacía ante cualquier norma jurídica local y por tanto el estado se encuentra obligado a adecuar sus normas de tal manera que no contravenga con las disposiciones de los distintos tratados que ha celebrado, por lo que resulta necesario, establecer qué es el control de convencionalidad y los efectos que causa frente a la jurisprudencia reconocida en nuestro país como obligatoria en el artículo 217 de la Ley de Amparo.

De esta forma, el control de convencionalidad, es el mecanismo que se ejerce para verificar que una ley, reglamento o acto de las autoridades del Estado, se ajustan a las normas, los principios y obligaciones de la Convención Americana de Derechos Humanos, principalmente, en la que funda la competencia contenciosa de la Corte Interamericana de Derechos Humanos (Bustillo, s.f.). Esto implica ampliar más el impacto de los compromisos internacionales, este fenómeno ha incitado una lucha entre el viejo y el nuevo método de justicia en los países de Latinoamérica, como México; es una idea creada para limitar o regular la conducta de los hombres, sin existencia real con base en conceptos como la propiedad, la justicia, la libertad, equidad, jurisdicción, intereses colectivos, etcétera.

La noción de control de la convencionalidad o de la "regularidad de normas, actos y omisiones ante estándares de fuente internacional", está inspirado en el "control de constitucionalidad" que es una forma común de referirse a uno de los sectores de la defensa de la constitución, el sector de garantía (complemento del de protección), que incluye a las diversas figuras y modalidades de la justicia constitucional o del derecho procesal constitucional, como también se le conoce (Carmona, s.f.). 
Desde este ángulo, podemos afirmar que existen dos grandes modalidades del control de convencionalidad (Carbonell, 2015) uno de ellos es el control supranacional o internacional, y otro es el doméstico, estatal o interno, esto es, uno se lleva a cabo a nivel internacional por órgano u órganos de esta índole y otro es el que corresponde efectuar a las autoridades en sede doméstica.

El control judicial de convencionalidad supranacional (García, 2011), es de carácter concentrado y es el que realizan tribunales supranacionales como la Corte Europea, Interamericana y africana de derechos humanos. Podría considerarse como control la actividad consultiva de los respectivos tribunales, en particular en el caso interamericano, cuando en una de sus modalidades le permite a la Corte analizar la regularidad de las leyes de algún estado con la Convención u otros tratados de derechos humanos, pues se asemejaría a un control abstracto de la constitucionalidad de las leyes (Carmona, s.f.).

Mientras que el control de convencionalidad interno (Ferrer, 2012), es el que correspondería realizar a los jueces en un determinado país, en particular cuando realizan labores de revisión de las leyes, actos u omisiones de las autoridades, incluyendo los de otros jueces de grados subsiguientes u órdenes diversos. Cabe destacar que los preceptos que contienen los tratados enuncian normas de diverso alcance, categoría y, por lo tanto, efectividad; hay normas cuya aplicación directa no importa mayor problema, toda vez que su redacción es tajante, no requieren ser detalladas legislativamente y, por lo general, no admiten excepciones. Entre estas se encuentran la prohibición de la tortura, la prohibición del restablecimiento de la pena de muerte en los Estados que la han abolido, la aplicación del principio non bis in ídem o la prohibición de penas trascendentales (Carmona, s.f.).

La jurisprudencia, en su significado gramatical, es “ciencia del Derecho y configura en otra acepción, la enseñanza doctrinal que dimana de las decisiones o fallos de autoridades gubernativas o judiciales, e incluso se entiende con la norma de juicio que suple omisiones de la ley, que se funde en prácticas seguidas en casos iguales y análogos" (Arellano, 2002).

En nuestro país es una fuente formal de derecho y así también es el medio por el cual se establece la garantía de legalidad de carácter jurisdiccional prevista en el último párrafo del numeral 14 de la Constitución Policita de los Estados Unidos Mexicanos, porque con ella se interpreta la constitución, tratados, la ley, así como los reglamentos de manera reiterada, hasta hacerse obligatoria.

La jurisprudencia es la institución del juicio de amparo, por virtud de la cual los tribunales federales competentes interpretan con sentido de justicia y equidad la ley cuando esta no es clara, con el objeto de resolver una controversia, con el agregado de que dicha interpretación debe ser firme y reiterada, además de obligatoria y deberá integrarse necesariamente de cinco ejecutoras ininterrumpidas que pronuncie la Suprema Corte de Justicia de la Nación en Pleno o en Salas, o que dicten los tribunales colegiados de circuito y también las que procedan de la determinación superior que dirima una contradicción de tesis (Carmona, s.f.).

En cuanto a la integración de la jurisprudencia, es necesario establecer que dicha integración está contemplada en el artículo 216 y 217 de la Ley de Amparo (2013), concediendo supremacía jerárquica a la Suprema Corte de Justicia de la Nación, para la interpretación jurídica, por lo que se desprende que deberá funcionar en pleno, esto significa que el criterio jurídico en nuestro país, recae en un órgano de mayor rango, nombrado así por la propia ley. 
Por disposición de la normatividad la jurisprudencia que establezca la Suprema Corte de Justicia de la Nación, funcionando en pleno o en salas, es obligatoria para éstas tratándose de la que decrete el pleno, y además para los Plenos de Circuito, los tribunales colegiados y unitarios de circuito, los juzgados de distrito, tribunales militares y judiciales del orden común de los Estados y de la Ciudad de México, tribunales administrativos y del trabajo, locales o federales. La jurisprudencia que establezcan los Plenos de Circuito es obligatoria para los tribunales colegiados y unitarios de circuito, los juzgados de distrito, tribunales militares y judiciales del orden común de las entidades federativas y tribunales administrativos y del trabajo, locales o federales que se ubiquen dentro del circuito correspondiente. La jurisprudencia que establezcan los tribunales colegiados de circuito es obligatoria para los órganos mencionados en el párrafo anterior, con excepción de los Plenos de Circuito y de los demás tribunales colegiados de circuito.

Obligatoriedad que con las reformas al sistema jurídico mexicano cada día es más cuestionable, pues los juzgadores tienen el deber de inaplicar todas aquellas disposiciones que contravengan derechos fundamentales, por lo que si una jurisprudencia se encuentra en este supuesto debe seguir tal suerte.

Sobre el particular es necesario analizar la contradicción de tesis 299/2013 (CT-299), resuelta por el Pleno de la Suprema Corte de Justicia (2013), en donde el tema a debatir es precisamente la posibilidad de que los jueces de los órganos jurisdiccionales inferiores no aplicaran, en un caso concreto, la jurisprudencia obligatoria de la Suprema Corte, esto por considerarla inconstitucional o incovencional.

Tema defendido por el ministro González de la Vega y la mayoría de los ministros, por lo que la argumentación para sustentar la no inaplicación de la jurisprudencia obligatoria que distingue en la citada resolución es que la jurisprudencia es obligatoria, porque así, lo marca la Ley de Amparo, adquiriendo así, el carácter de norma general, de no ser así, no existiría seguridad jurídica al momento que los jueces inferiores emitieran sus resoluciones.

La postura de la minoría de los ministros de la que destacan los votos de los juristas Juan Silva (2012) y José Ramón Cossió Díaz, alude a la necesidad de aplicar en todo momento las normas que más favorezca a las partes en un caso concreto, abandonando las ideas tradicionalistas, para dar paso a la labor interpretativa de los jueces en el marco del respeto de los derechos humanos.

\section{DISCUSIÓN}

La adopción de la doctrina de control de convencionalidad en el sistema jurídico mexicano es determinante para inaplicar la jurisprudencia que contravenga derechos fundamentales, es decir, para inobservar su obligatoriedad.

En ese sentido, el Estado al reconocer los derechos humanos en la Constitución, debe entonces, ajustar sus ordenamientos legales a efectos que estos no contravengan las determinaciones o sentido fundamental de los tratados internacionales de los cuales se forma parte, garantizando así la mayor protección de la persona. Por lo que no debería existir duda para los órganos jurisdiccionales, al momento de desaplicar una jurisprudencia, cuando esta contravenga el orden convencional.

Por tanto, que los juzgadores mexicanos tienen en el control de convencionalidad una herramienta para ser eficiente su labor, instrumento que a la luz de los compromisos internacionales que ha asumido México resulta obligatoria, por lo que no cabe duda que ante una norma que contravenga las disposiciones protectoras de derechos humanos habrá de preferirse aquella que lo salvaguarde. 


\section{REFERENCIAS}

1. Arellano Hobelsberger, Walter. (2002). La seguridad jurídica en el actual sistema jurisprudencial mexicano, Revista del Instituto de la Judicatura Federal, 10, 19-38.

2. Bazán, Víctor. (2011). El control de convencionalidad: incógnitas, desafíos y perspectivas, en Víctor Bazán y Claudio Nash (coord.), Justicia Constitucional y Derechos Fundamentales. El control de convencionalidad. Fundación Konrad Adenauer, Colombia.

3. Bustillo Marín, Roselia. (s.f.). El control de convencionalidad: la idea del bloque de constitucionalidad y su relación con el control de constitucionalidad en materia electoral. Tribunal electoral, México.

4. Carbonell, Miguel. (2015). El ABC de los derechos humanos y del control de convencionalidad. Porrúa, México.

5. Carmona Tinoco, Jorge Ulises. (s.f.). Apuntes del control de convencionalidad, Centro de Estudios Jurídicos Carbonell, A.C., México.

6. Kelsen, Hans. (2009). Teoría pura del derecho. Porrúa, México.

7. Corte IDH. (2009). Caso Radilla Pacheco vs. México. Excepciones Preliminares, Fondo, Reparaciones y Costas. Costa Rica.

8. Corte IDH. (2006). Sentencia de la corte interamericana de derechos humanos en el caso Vargas Areco vs. Paraguay. Costa Rica.

9. Corte IDH. (2004). Sentencia de la corte interamericana de derechos humanos en el caso Tibi vs. Ecuador. Costa Rica.

10. Corte IDH. (2003). Sentencia de la corte interamericana de derechos humanos en el caso Myrna Mack Chang vs Guatemala. Costa Rica.

11. Diario Oficial de la Federación. (2013). Ley de amparo, reglamentaria de los artículos 103 y 107 de la Constitución Política de los Estados Unidos Mexicanos. México.

12. Ferrer Mac-Gregor, Eduardo. (2012). El control de convencionalidad y la reforma Constitucional en materia de Derechos Humanos. Centro de Estudios, Derechos e Investigaciones Parlamentarias, Serie azul.

13. García Ramírez, Sergio. (2011). Control judicial interno de convencionalidad. Revista jurídica de ciencias jurídicas de Puebla, 28.

14. Silva Nava, Carlos de. (2012). La Jurisprudencia creación Jurisdiccional de derecho. Themis, México.

15. SCJN. (2014). Tesis: P./J. 64/2014 (10a.), Gaceta del Semanario Judicial de la Federación, Libro 13, Décima Época, Tomo I. México.

16. SCJN. (2013). Contradicción de tesis 299/2013 (CT-299). México.

17. SCJN. (2011). Acuerdo general número 9/2011. Novena época, México.

18. SCJN. (1999). Tesis: P. LXXVII/99. Semanario Judicial de la Federación y su Gaceta, Novena época, Tomo X, México. 